IZA DP No. 9766

Doing Your Best When Stakes Are High?

Theory and Experimental Evidence

Nicolas Houy

Jean-Philippe Nicolaï

Marie Claire Villeval

February 2016 


\title{
Doing Your Best When Stakes Are High? Theory and Experimental Evidence
}

\author{
Nicolas Houy \\ Université de Lyon, CNRS, GATE \\ Jean-Philippe Nicolaï \\ ETH Zürich \\ Marie Claire Villeval \\ Université de Lyon, CNRS, GATE, \\ IZA and University of Innsbruck
}

Discussion Paper No. 9766

February 2016

IZA

P.O. Box 7240

53072 Bonn

Germany

Phone: +49-228-3894-0

Fax: +49-228-3894-180

E-mail: iza@iza.org

Any opinions expressed here are those of the author(s) and not those of IZA. Research published in this series may include views on policy, but the institute itself takes no institutional policy positions. The IZA research network is committed to the IZA Guiding Principles of Research Integrity.

The Institute for the Study of Labor (IZA) in Bonn is a local and virtual international research center and a place of communication between science, politics and business. IZA is an independent nonprofit organization supported by Deutsche Post Foundation. The center is associated with the University of Bonn and offers a stimulating research environment through its international network, workshops and conferences, data service, project support, research visits and doctoral program. IZA engages in (i) original and internationally competitive research in all fields of labor economics, (ii) development of policy concepts, and (iii) dissemination of research results and concepts to the interested public.

IZA Discussion Papers often represent preliminary work and are circulated to encourage discussion. Citation of such a paper should account for its provisional character. A revised version may be available directly from the author. 
IZA Discussion Paper No. 9766

February 2016

\section{ABSTRACT}

\section{Doing Your Best When Stakes Are High? Theory and Experimental Evidence*}

Achieving an ambitious goal frequently requires succeeding in a sequence of intermediary tasks, some being critical for the final outcome, and others not. Individuals are not always able to provide a level of effort sufficient to guarantee success in all the intermediary tasks. The ability to manage effort throughout the sequence of tasks is therefore critical. In this paper we propose a criterion that defines the importance of a task and that identifies how an individual should optimally allocate a limited stock of exhaustible efforts over tasks. We test this importance criterion in a laboratory experiment that reproduces the main features of a tennis match. We show that our importance criterion is able to predict the individuals' performance and it outperforms the Morris importance criterion that defines the importance of a point in terms of its impact on the probability to achieve the final outcome. We also find no evidence of choking under pressure and stress, as proxied by electrophysiological measures.

JEL Classification: C72, C92, D81

Keywords: critical ability, choking under pressure, Morris-importance, Skin Conductance Responses, experiment

Corresponding author:

Marie Claire Villeval

CNRS, GATE Lyon St Etienne

93, Chemin des Mouilles

F-69130, Ecully

France

E-mail: villeval@gate.cnrs.fr

\footnotetext{
* We are grateful to Mateus Joffily for assistance in the analysis of Skin Conductance Responses. This research has been supported by a grant of the LABEX CORTEX (ANR-11-LABX-0042) of Université de Lyon, within the program Investissements d'Avenir (ANR-11-IDEX-007) operated by Agence Nationale de la Recherche.
} 


\section{Introduction}

Any professional life is composed of a myriad of trials and hardships. Each one of these sequences is a dynamic experience with various tasks to achieve, each demanding endeavours in order to meet a final, greater objective. These successive tasks do not necessarily have the same importance when it comes to achieve the final goal. Some tasks are of irreversible nature, i.e. failing to perform them successfully will impede the achievement of the final goal (think, for example, of the completion of a $\mathrm{Ph}$.D. to become an academics), while failures in other tasks (for example, being put in difficulty during a seminar presentation) can be compensated by success in other ones (for example, making an excellent impression after the presentation of another research paper). The respective importance of these tasks will impact the behavior of agents, especially when they have to compete with others. Indeed, individuals are not always able to provide a level of effort sufficient to guarantee success in all the tasks. The ability to manage effort throughout the sequence of tasks is therefore critical. First, important stakes i.e. the ones essential to achieve the final greater objective - may generate stress that affects behavior. Second, agents who are free to allocate their time and energy as they wish, may be more inclined to exert more effort on these more important tasks. The importance assigned to each task will certainly influence performance. The following question then arises: does performance adjust to the importance of the task to undertake? Illustrations outside of the professional domain can be provided by a tennis match. The degree of importance given to each point by an individual varies according to its potential impact on the final outcome of the match. A match point is more important than the first point of the match. If an individual loses a match point, he may not be given another chance to win the match in the future. It is therefore likely that the individual will concentrate his energy on winning this point. Meanwhile, the level of stress probably increases with the importance of this point, which may affect the probability of success negatively if the individual chokes under pressure. The ability to allocate optimally effort across points (or tasks, more generally) may be therefore fundamental for wining a competition. This requires identifying the relationship between the importance of a task, effort and performance. This is precisely the aim of this paper that 
considers a dynamic framework and a decision process that develops over time to achieve a high-stake goal.

The relationship between the importance of the task, effort allocation and performance lies at the crossroads of economics and psychology. The idea of choking under pressure was first developed to demonstrate that the importance of a stake may generate pressure that will have negative effects on performance. In particular, Baumeister (1984) showed that pressure increases with the existence of competition between agents. Ariely et al. (2009) further showed in a series of field and lab experiments that very high monetary stakes tend to hurt performance because they generate supra motivation and excess stress. Using soccer penalty shootouts, Apesteguia and Palacios-Huerta (2010) found that in sequential tournaments the fist kicking teams won more frequently, and suggest that psychological pressure distinct from high stakes has a detrimental effect on performance; this first-mover advantage has been challenged, however, by Kocher et al. (2012) by using a larger sample set (see also Dohmen (2008) about football competitions).

More recently, González-Díaz et al. (2012) coined the concept of critical ability that focuses on the capacity of an agent to adapt his performance to the size of the stake. The authors insist in particular on the individual heterogeneity in critical ability. Three interpretations of the concept are proposed by the authors. The critical ability may first be interpreted as the ability to deal with psychological pressure. Such interpretation appears close to the choking under pressure theory except that instead of being inefficient due to the pressure, the agent who possesses such a critical ability is not reactive to a stressful environment. A second interpretation considers the critical ability as a special skill in allocating limited resources optimally across a set of actions. A third interpretation is the ability of an individual to understand when some situations are more crucial than others. The authors apply this concept to tennis players. The stake of each point in a match is defined in terms of the Morris-importance criterion (Morris (1977)), which is the impact of winning this precise point on the probability of winning the match. Using the Association of Tennis Professionals (ATP) Ranking as a proxy to performance, the authors analyze the relation between Morris-importance and the 
ATP ranking. They show that a player's higher critical ability helps predicting his overall career success and they conclude that success depends on the ability to respond to pressure appropriately. However, they do not formally define the critical ability, their paper assuming that critical ability means to perform well when Morris-importance is high.

In contrast, the present paper lays theoretical foundations to critical ability in a decision theory setting and it assesses how performance during successive tasks is affected by stakes. Precisely, we retain the notion of critical ability as the capacity for a player to focus his efforts on the most important tasks, but we differ from González-Díaz et al. (2012) in that we develop a different notion of importance. We consider a situation in which individuals have a stock of exhaustible efforts that they can use to increase performance only for one state each, and they have to decide how to allocate them throughout the successive states. While choosing the ideal moment to make an effort, the agent faces a trade-off between the immediate gain of being successful at a given state and the option value related to the possibility of using this effort latter. This trade-off depends obviously on the state but also on the number of efforts left. This paper proposes then a criterion - the $\operatorname{HNV}(k)$-importance - which determines whether it is worth to make an effort at a given state when $k$ exhaustible efforts are left. We show that the two measures (Morris-importance and $\operatorname{HNV}(k)$-importance) are significantly different in the seminal framework of a simplified tennis match.

To test which criterion of importance better predicts behavior, we have designed a laboratory experiment that reproduces the same rules of point assignment than in a tennis match. We use a novel real effort task that consists in using the mouse pointer to reach the center of a target that appears on the computer screen. Participants have to shoot as accurately as possible in the center of the target. However, the difficulty lies in the fact that a random perturbation is dynamically applied to the mouse position. The difficulty is the same for each participant. The point is won by the participant in the pair whose shot is the closest to the target. The payoffs in the game depend on the final outcome of the competition. Similar to a tennis match, the first participant in the pair who wins at least four points with at least two points ahead of his opponent wins a round. The first participant who wins at least six 
rounds wins a set, and the first one who wins two sets wins the match. The experiment consists of two treatments, the Human treatment and the Robot treatment. While in the Human treatment participants in the same session are paired together, in the Robot treatment each participant is paired with a robot. On each point the robot is randomly assigned the performance of previous participants at any moment of the match. The comparison of the two treatments indicates how strategic considerations about the opponent's play can affect how importance influences the assignment of efforts. In each treatment and for each participant, we calculate for each score the Morris-importance and the $\mathrm{HNV}(k)$-importance. Of course, we ignore the stock of efforts available for each participant. Thus, we consider various situations in which the stock of efforts is arbitrarily set at 10,20,30, 40 and 50 at the start of the session. Moreover, to characterize the degree of stress experienced by the participants during a match, we use electrophysiological measures. Specifically, we record continuously the subjects' Skin Conductance Responses (SCR) that are considered as a measure of emotional arousal.

Our main findings show that the Morris-importance criterion fails at predicting participants' performance while the HNV-importance criterion predicts it. This finding holds both when assuming that all participants are endowed with the same initial stock of efforts (of various sizes) in the Human treatment and when allowing each participant to differ in his stock of efforts in both treatments. Also, we do not find evidence of choking under pressure: stress, as measured by the Skin Conductance Responses, does not affect performance in the Human treatment. This contrasts notably with Apesteguia and Palacios-Huerta (2010).

The remainder of this paper is structured as follows. Section 2 presents the modeling assumptions and the theoretical results. Section 3 details the experimental design and procedures. Section 4 presents the experimental results. Section 5 concludes. 


\section{Theoretical analysis}

\subsection{Set-up}

This paper considers various states and focuses on both the relationship between importance and states, and the relationship between importance and performance.

\subsubsection{States}

Let $S$ be a set of states. We add two absorbing states: $\{W\}$ where the individual wins (or where the individual has definitely reached his goal) and $\{L\}$ where he loses (or where the individual has definitely failed at reaching his goal). Let $S^{*}=S \cup\{W\} \cup\{L\}$. We denote by $\Pi\left(S^{*}\right)$ the set of probability distribution over $S^{*}$. We define a transition probability between states $p: S^{*} \times S^{*} \rightarrow[0 ; 1]$ such that $\forall s \in S^{*}, p(s,.) \in \Pi\left(S^{*}\right)$, and $p(\{W\},\{W\})=1$ and $p(\{L\},\{L\})=1$.

First, we define the probability that, starting from a given state, the individual reaches his final goal - state $\{W\}$ - at some time.

Definition 1. (Probability to reach the final goal) We call $P: S^{*} \rightarrow[0,1]$ the probability to reach the final goal. It is usually referred to as the probability to hit state $\{W\}$ and it is the minimal ${ }^{1}$ non-negative solution to the following system:

$$
\left\{\begin{array}{l}
P(\{W\})=1 \\
\forall s \in S \cup\{L\}, P(s)=\sum_{s^{\prime} \in S^{*}} p\left(s, s^{\prime}\right) P\left(s^{\prime}\right)
\end{array}\right.
$$

Let us give an intuition for the linear system given in Definition 1. Let us assume an individual in state $s \in S$. He can reach states $s_{1}, s_{2}, \ldots$ with probabilities $p_{1}=p\left(s, s_{1}\right)$, $p_{2}=p\left(s, s_{2}\right), \ldots$ respectively. Conditionally on being in $s_{1}$ (resp. $\left.s_{2}, \ldots\right)$, his probability to reach the final goal is $P\left(s_{1}\right)$ (resp. $\left.P\left(s_{2}\right), \ldots\right)$. Then, $P(s)$ is the sum of the conditional probabilities to reach the final goal in latter states, weighted by the transition probability to reach those states as next step.

\footnotetext{
${ }^{1}$ If $P$ is a minimal solution and $P^{\prime}$ is any solution, then $\forall s \in S^{*}, P(s) \leq P^{\prime}(s)$. For more details, see Norris (1998).
} 
Let us define function $s^{+}: S \rightarrow S^{*}$ as the transition function when the individual is successful at a given state. We say that an individual is successful in state $s \in S$ when he moves towards the next attainable state with the highest $P$ value. Formally, ${ }^{2}$

$$
\forall s \in S, s^{+}(s)=\arg \max _{s^{\prime} \in S^{*}, p\left(s, s^{\prime}\right)>0} P\left(s^{\prime}\right) .
$$

Similarly, we consider the function $s^{-}: S \rightarrow S^{*}$ as the transition function when the individual is not successful at a given state.

$$
\forall s \in S, s^{-}(s)=\arg \min _{s^{\prime} \in S^{*}, p\left(s, s^{\prime}\right)>0} P\left(s^{\prime}\right) .
$$

In order to define the importance of a given state, we use the probability function $P$ and adapt $^{3}$ the measure proposed by Morris (1977) for the case tennis points to our decision theory setting. ${ }^{4}$

Definition 2. (Morris-importance) The measure of importance of a state $s$ is given by the function $I: S \rightarrow \mathbb{R}$, defined as: $\forall s \in \mathcal{S}$,

$$
I(s)=P\left(s^{+}(s)\right)-P\left(s^{-}(s)\right) .
$$

The function $I$ corresponds to the absolute difference in the probability to reach the final goal for a given state, according to whether the individual is successful or not at this specific state. In other words, the Morris-importance is given by the impact of being successful or not on the probability to reach the final goal.

\footnotetext{
${ }^{2}$ For the sake of simplicity, we consider the function $s^{+}$defined onto $S^{*}$ whereas it should more rigorously be set-valued.

${ }^{3}$ Because we are not dealing with binary outcome in each state, it may be argued that other adaptations are more natural or suitable. This will make no difference for the remainder of the paper and a study of this adaptation is left for further work.

${ }^{4}$ This concept is also used in Magnus and Klaassen (1998), Paserman (2007) and González-Díaz et al. (2012). However, González-Díaz et al. (2012) further use conditional probabilities which allows them to decompose the Morris-importance into the constituent probabilities of winning at the various hierarchical levels of the match.
} 


\section{$2.2 \quad$ Stock and allocation of efforts}

Assume, now, that the individual has some available stock of efforts. If an effort is exerted, the probability to be successful at this state is equal to one. This stock of efforts is independent of the transition probability of an individual. We assume that individuals are able to recognize the importance of a state. Efforts are exhaustible (an effort can be used only once) and limited. Note that individuals have the possibility to choose whether to use the effort or not and they have no obligation to exhaust their stock of efforts. For instance, if at some state $s \in \mathcal{S}$, there exists $s^{\prime} \in \mathcal{S}$ such that $p\left(s, s^{\prime}\right)=1$, then the individual does not have any strict incentive to make an effort. We define function $V$ as the probability for an individual to reach his final goal with a given stock of efforts to be used optimally.

Definition 3. (Probability to reach the final goal with a stock of efforts.) Consider $V: \mathbb{N} \times S^{*} \rightarrow \mathbb{R}$ the probability to reach the final goal depending on the number of efforts left to make and at a given state. $V$ is the minimal non-negative solution to the following system: ${ }^{5}$ $\forall s \in S, V(0, s)=P(s)$ and $\forall k \in \mathbb{N}$ with $k>0$,

$$
\left\{\begin{array}{l}
V(k,\{W\})=1 \\
\forall s \in S \cup\{L\}, V(s)=\max \left\{V\left(k-1, s^{+}(s)\right), \sum_{s^{\prime} \in S^{*}} p\left(s, s^{\prime}\right) V\left(k, s^{\prime}\right)\right\}
\end{array}\right.
$$

In order to understand the function displayed in Definition 3, two cases should be considered. First, let us consider that one effort is used in the current state. In this case the individual is successful and the probability to reach the final goal is equal to the probability to reach it from the state that the individual reaches after being successful, only with one effort less. Second, if the individual does not use an effort, the probability to reach the final goal is equal to the expected probability to reach the final goal over the next steps but with no change to his stock of efforts. The individual maximizes over the two cases, as we make the assumption that individuals are infinitely far-sighted optimizers.

We propose in this paper an importance criterion that will depend on how worthy it is to use an effort in a specific state, taking into account the number of efforts left.

\footnotetext{
${ }^{5}$ Proof of existence and uniqueness is similar to the one for function $P$ and is therefore omitted.
} 
Definition 4. (HNV(k)-importance) The $H N V(k)$-importance when $k>0$ efforts are left and at state $s \in \mathcal{S}$ is given by:

$$
H N V(k)=V\left(k-1, s^{+}(s)\right)-\sum_{s^{\prime} \in S^{*}} p\left(s, s^{\prime}\right) V\left(k, s^{\prime}\right)
$$

This measure is the difference between the probabilities corresponding to the two cases we previously described: either one effort is used or the effort is kept to be used later. In other words, this measure determines the incentive to make an effort. When it is positive, it means that it is worth using an effort. When the measure is high, it means that the incentive to use an effort is high.

\subsection{Differences between Morris-importance and HNV-importance}

To sum up, Morris-importance defines the concept of importance as a measure of how closer to the final goal an individual gets when being successful at an intermediary task compared to being unsuccessful. Differently, HNV-importance defines the concept of importance as the incentive to make an effort when this one ensures the success in an intermediary task. Both definitions rely on the idea that a state should be labeled important when success at this state makes reaching the final goal more probable. Here, we propose to check for the correlations of the two definitions of importance in a simple illustration.

In order to do that, we use the seminal framework of a simplified tennis match as it is widely used in the literature. This framework allows to observe a large diversity of point importance - with both definitions - due to the ratchet effect of game points and set points for instance. More specifically, we consider two different levels of stages, an elementary stage and a crucial one. To reach the elementary stage, the individual should be successful at a minimum of 4 acts with at least 2 acts more than the number of acts for which he is unsuccessful. To reach the crucial stage the individual should be successful at six intermediary stages. If he is unsuccessful at least at six elementary stages, he fails at a crucial stage. We assume that, to reach his goal, the individual should be successful at two crucial stages and be unsuccessful at one crucial stage maximum. We calculate the correlations between Morris-importance and 
$\operatorname{HNV}(k)$-importance, for $k$ equal to $1,2,3,4$ and 5, considering various arbitrary transition probabilities: $10 \%, 20 \%, 30 \%, 40 \%, 50 \%, 60 \%, 70 \%, 80 \%$ and $90 \%$. Table 1 depicts these results.

\begin{tabular}{|l|l|l|l|l|l|l|l|l|l|}
\hline Probability $p$ & $10 \%$ & $20 \%$ & $30 \%$ & $40 \%$ & $50 \%$ & $60 \%$ & $70 \%$ & $80 \%$ & $90 \%$ \\
\hline Correlation (Morris, HNV(1)) & 0.61 & 0.43 & 0.04 & -0.12 & 0.43 & -0.12 & 0.04 & 0.43 & 0.61 \\
Correlation (Morris, HNV(2)) & 0.06 & 0.04 & -0.04 & -0.04 & 0.46 & 0.07 & 0.39 & 0.74 & 0.83 \\
Correlation (Morris, HNV(3)) & 0.01 & 0.03 & 0.06 & 0.14 & 0.48 & 0.26 & 0.62 & 0.89 & 0.98 \\
Correlation (Morris, HNV(4)) & -0.00 & 0.03 & 0.07 & 0.21 & 0.46 & 0.36 & 0.69 & 0.90 & 0.97 \\
Correlation (Morris, HNV(5)) & -0.01 & 0.02 & 0.07 & 0.24 & 0.42 & 0.40 & 0.71 & 0.89 & 0.97 \\
\hline
\end{tabular}

Table 1: Correlations between Morris-importance and $\operatorname{HNV}(k)$-importance, for $k$ equal to 1 , 2, 3, 4 and 5, depending on the transition probability $p$.

The correlation between the Morris-importance and the HNV(1)-importance varies from 0.61 to -0.12 . More specifically, the correlation is very low for the transition probabilities $p=30 \%, 40 \%, 60 \%$ and $70 \%$. When $k>1$, the two measures are correlated only when the transition probability is very high. For low transition probabilities, correlations are close to zero.

Then, we conclude that the two measures are significantly different and that this difference justifies further investigation at the validity of the link between importance and performance. In the remainder of this article, we use an experiment to check which definition of importance is better at explaining performance.

\section{Experimental design and procedures}

\subsection{Experimental design}

In order to test these different approaches of importance and analyze which criterion has the highest predictive power of performance in a real effort task, we have designed a laboratory experiment. The experiment consists of two treatments, the Human treatment and the Robot treatment. We used a between-subject design. The main difference between these two treatments is that when an individual faces a robot opponent in our game he does not have to form beliefs about how the other individual will use his efforts strategically. Let us describe each of 
these treatments successively.

The Human treatment In the Human treatment we pair participants at the beginning of the session. Each pair member has to compete to win a prize. To win the prize, the two competitors have to perform several rounds of a real-effort task. This task consists in using the mouse pointer to reach the center of a target that is displayed on the computer screen (see Figure 1). Participants have to shoot as accurately as possible in the center of the target. The measure of performance is given by the Euclidean distance in pixels between the impact of the shot and the center of the target. The smaller the distance is, the better the performance. The difficulty of the task comes from a continuous perturbation of the mouse position that is random in each trial (giving the impression of a trembling hand). The perturbation is different across subjects but it is drawn from the same distribution. In a trial, each participant has 8 seconds maximum to shoot. If the shot has not been performed in 8 seconds, it is considered as missing in the current trial.

The payoffs in the game depend on the outcome of the competition. The winner of the game earns 20 Euros while the loser gets nothing. The game consists of several trials, rounds and sets. In a given trial, the competitor with the best performance (that is to say, the lowest distance to the center of the target) scores one point. In case of a tie between the two participants, a random draw determines which one is awarded the point. The first of the two competitors who wins at least 4 points with at least 2 points ahead of the opponent wins the round. The first of the two competitors who wins 6 rounds wins the set. The first of the two competitors who wins 2 sets wins the match. There is one match in each session. As indicated in Figure 1, participants are permanently informed on the number of points, rounds and sets they and their opponent have won so far.

Before the game starts, participants can make 5 test shots and 10 practice shots and receive feedback on the distance to the target after each shot. The test shots are intended to familiarize them with the task. The practice shots are used to calculate each participant's ability. This captures the permanent ability of the participant, independent of his critical ability (i.e., his capacity to recognize important points and focus his efforts on these important 


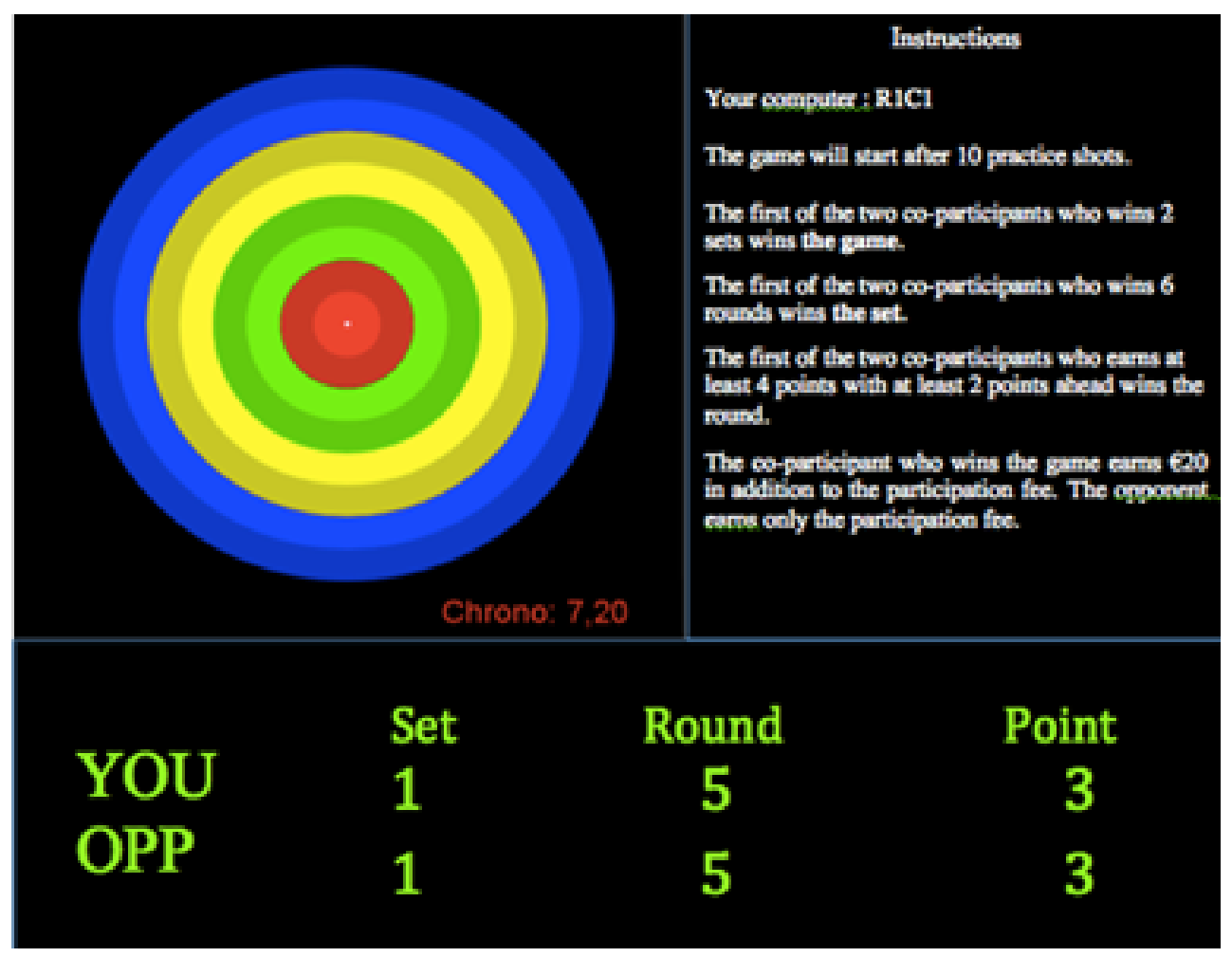

Figure 1: Screenshot of the task. 
points). The program compares the participant's performance in each of the practice shots to the performance of his opponent, taking into account all possible combinations of these shots (ignoring the shots that have not been done before time elapsed). At the beginning of the actual game, participants receive information about the theoretical number of chances out of 100 that they should win a point on their opponent for a given shot. ${ }^{6}$

The Robot treatment In the Robot treatment participants are informed that they are paired with a robot. It is also made common knowledge that the robot does not shoot at random: we assigned the performances of participants in previous sessions to each robot. It means that each shot is an actual shot, but played independently on the current human opponent. The robot's shot can also come from any period of the match (i.e., when the human subject plays a match point, the robot's shot is not selected among the previous match points but among all points). Here, a human participant should try to shoot as accurately as possible regardless of his beliefs about his opponent's play since this opponent cannot elaborate a strategy in response to his own play. The rules of the game are similar in this treatment to that used in the Human treatment. Like in the Human treatment, participants receive information at the beginning of the game about the theoretical number of chances out of 100 that they should win a point on their opponent. The difference is that the program compares the participant's performance in each of the practice shots to the performance in the same practice shots of different subjects in previous sessions, taking into account all possible combinations of these shots.

To study the impact of stress on performance, we also measured emotional arousal continuously during the game. This gives us an index of stress. We were able to record electrophysiological measures simultaneously for 12 participants per session (in total, 48 subjects were recorded in the Human treatment and 24 in the Robot treatment). Since some of the participants were not recorded, we can control for whether or not emotions recording influences performance. We take the Skin Conductance Responses (SCR) as a measure of physiological

\footnotetext{
${ }^{6}$ Indeed, in most actual sport or occupational tournaments, when they start competing, competitors are aware of their relative ability compared to that of their opponents, based on previous records of performance.
} 
arousal associated with an emotional state. SCR were continuously recorded until the end of the session, in a noiseless environment with a stable temperature set to $21^{\circ} \mathrm{C}$. Skin conductance is analyzed in response to three events. (a) The first is during the time interval between the display of the target and the moment the shot is taken. (b) The second event of interest is the time of receipt of feedback about one's own performance. (c) The third event is the time of receipt of feedback on the opponent's performance (thus, on who wins the point). We imposed a minimum of 5 seconds between the second and third events when sending feedback to the subjects in order to avoid the overlapping of emotional arousals related to two different events. For the first event, SCR are analyzed within a time window with variable duration across subjects and trials since shots are self-paced (between 5 and 8 seconds). ${ }^{7}$ For the next two events, the time window is fixed at one to three seconds after the onset of these events to capture the onset of the response and determine whether there is a significant arousal. While emotional arousal is detected within the time window, the SCR magnitude may be given by the observation after the time window. The data analysis is based on this magnitude. ${ }^{8}$

At the end of the experiment, a brief demographic questionnaire was administered, including questions on gender and age. We also inquired about the practice of tennis since familiarity with its rules may possibly help participants in our game.

\subsection{Procedures}

The computerized experiment was conducted at GATE-LAB, Lyon, France. 103 participants were recruited from local engineering and business schools, using ORSEE (Greiner et al. (2004)). We ran four sessions for the Human treatment and two for the Robot treatment, with respectively 70 and 33 participants. Summary statistics on participants are reported in

\footnotetext{
${ }^{7}$ If the participant shoots in less than 5 seconds after the target appears on the screen, the window of analysis includes a minimum of five seconds. If the participant shoots between five and eight seconds, the window analysis is the time between the display of the target and the timing of the shot.

${ }^{8}$ The signal was low-pass filtered at $0.5 \mathrm{~Hz}$ offline, using a 5 th order Butterworth low-pass digital filter. The onset and peak of the SCR were detected when the first derivative of the filtered signal changed sign thanks to a routine written in Matlab (The MathWorks Inc., USA). Onsets were identified by a negative to positive zero crossing. Peaks were identified by a positive to negative zero crossing. The SCR amplitude was calculated as the difference between the signal amplitude at the peak and the onset times. It was thresholded at 0.02 $\mu \mathrm{S}$. The whole signal was visually inspected prior to further analysis and ectopic response was removed. The analysis assigns zero amplitude to the subjects without a measurable response (Dawson et al. (2007)).
} 


\begin{tabular}{crrr}
\hline & $\begin{array}{r}\text { All } \\
\text { treatments }\end{array}$ & $\begin{array}{r}\text { Human } \\
\text { treatment }\end{array}$ & $\begin{array}{r}\text { Robot } \\
\text { treatment }\end{array}$ \\
\hline Number of sessions & 6 & 4 & 2 \\
Number of participants & 103 & 70 & 33 \\
Percentage of players with SCR measured & 69.90 & 68.57 & $72.73 \mathrm{~ns} \mathrm{PT}$ \\
Percentage of males & 40.78 & 44.29 & $33.33 \mathrm{~ns} \mathrm{PT}$ \\
Mean age & $21.68(3.18)$ & $21.77(3.45)$ & $21.48(2.54) \mathrm{ns} \mathrm{MW}$ \\
Percentage with tennis experience & 28.16 & 27.14 & $30.33 \mathrm{~ns} \mathrm{PT}$ \\
Mean distance in the 10 practice shots & $7.80(0.77)$ & $7.73(0.75)$ & $7.95(0.78) \mathrm{ns} \mathrm{MW}$ \\
\hline
\end{tabular}

Note: Standard deviations are in parentheses. ns: non significant. PT: proportion test, with one individual as one independent observation. MW: Mann-Whitney tests. All tests are two-sided.

Table 2: Summary statistics on participants.

Table 2. Based on non-parametric statistics, the composition of the two treatment samples does not differ significantly in terms of percentage of subjects with SCR measured, gender, age, practice of tennis and ability in the game. Permanent ability (distinct from critical ability) is measured as the average distance to the center of the target in the ten practice shots (excluding the shots after allowed time).

Upon arrival, participants drew a tag from a bag that determined their random assignment to a computer terminal. Next, each participant whose SCR were measured had to wash their hands with a neutral soap. Then, an experimentalist put electrodes on the non-dominant hand to be kept until the end of the session. After checking the quality of the signal recording, the set of instructions were distributed to all participants and read aloud. The understanding of participants was checked by means of a questionnaire and questions were answered in private.

On average, a session lasted about 60 minutes, including payment. The participants were paid their earnings from the game (either 20 euros or 0) in addition to a 5 euros show-up fee. On average, participants earned 14.90 euros (S.D.=10.05). We paid participants individually in cash and in private in a separate room immediately at the end of the session.

\section{Experimental results}

Table 3 gives a brief overview of descriptive statistics relative to the two treatments. The last column reports non-parametric tests comparing the two treatments. In these tests, one mean 


\begin{tabular}{|c|c|c|c|}
\hline & $\begin{array}{c}\text { All } \\
\text { treatments }\end{array}$ & $\begin{array}{l}\text { Human } \\
\text { treatment }\end{array}$ & $\begin{array}{l}\text { Robot } \\
\text { treatment }\end{array}$ \\
\hline $\begin{array}{l}\text { Mean distance to the target } \\
\text { (in pixels) }\end{array}$ & $7.68(5.47)$ & $7.60(5.15)$ & $7.86(6.08) * * \mathrm{MW}$ \\
\hline $\begin{array}{l}\text { Mean time to shoot } \\
\text { (in milliseconds) }\end{array}$ & $3314.56(1611.42)$ & $3423.07(1687.53)$ & 3087.16 (1412.30) ns MW \\
\hline $\begin{array}{l}\text { Mean number of shots } \\
\text { Percentage round shots }\end{array}$ & $153.54(42.95)$ & $152.94(42.79)$ & $154.82(43.92)$ ns MW \\
\hline $\begin{array}{c}\text { (i's advantage) } \\
\text { Percentage set shots }\end{array}$ & 12.68 & 12.67 & $12.70 \mathrm{~ns} \mathrm{MW}$ \\
\hline (i’s advantage) & 0.94 & 0.96 & $0.88 \mathrm{~ns} \mathrm{MW}$ \\
\hline $\begin{array}{l}\text { Percentage match shots } \\
\text { (i's advantage) }\end{array}$ & 0.70 & 0.72 & $0.67 \mathrm{~ns} \mathrm{MW}$ \\
\hline $\begin{array}{l}\text { Percentage of winning } \\
\text { subjects }\end{array}$ & 49.51 & 50.00 & $48.48 \mathrm{~ns}$ binomial test \\
\hline Mean Morris & $0.05(0.06)$ & $0.05(0.06)$ & $0.05(0.06) \mathrm{ns} \mathrm{MW}$ \\
\hline Mean HNV & $0.09(0.29)$ & $0.09(0.28)$ & $0.10(0.30) \mathrm{ns} M W$ \\
\hline $\begin{array}{l}\text { Mean SCR amplitude } \\
\text { at presentation of the target } \\
\text { Mean SCR amplitude }\end{array}$ & $0.03(0.12)$ & $0.02(0.09)$ & $0.04(0.17) \mathrm{ns} \mathrm{MW}$ \\
\hline $\begin{array}{l}\text { at feedback on own score } \\
\text { Mean SCR amplitude }\end{array}$ & $0.122(0.178)$ & $0.113(0.164)$ & $0.145(0.208) \mathrm{ns} \mathrm{MW}$ \\
\hline at feedback on trial outcome & $0.110(0.178)$ & $0.103(0.175)$ & $0.126(0.183) \mathrm{ns} \mathrm{MW}$ \\
\hline
\end{tabular}

Table 3: Summary statistics on the games.

value for each individual for the whole game is taken as one independent observation.

Table 3 indicates a significant difference between treatments in terms of performance (distance to the target, $\mathrm{p}=0.046)$, but no difference regarding time to shoot, duration of the match, percentage of round/set and game shots at the advantage of the individual, and emotional arousal. We introduce our first result.

Result 1: Approaches based either on the nature of the shot (round/set/match shots vs. regular shots) or on the Morris criterion of importance fail at predicting participants' shot performance. Players do not choke under pressure.

Support to Result 1. To compare the predictive values of our different importance criteria, we use an econometric analysis in which the dependent variable is the player's performance captured by the distance of the shot to the center of the target in each trial. We estimate 
linear regressions with robust standard errors clustered at the individual level. In all the econometric models reported in the remainder of this section, the independent variables include the complexity of the current shot, the time to shoot, the shot number in the game. The "Distance practice" variable is the mean distance to the center of the target in the ten practice shots: the higher is this distance, the lower is the player's permanent ability. Complexity is measured by the sum of the net perturbations of the trajectory during 250 milliseconds before the shot. ${ }^{9}$ We control for whether the player's electrodermal responses were recorded or not and for the magnitude of the emotional arousal at the time of the shot. ${ }^{10}$ We also include controls for gender, age and practice of tennis. Our variable of interest is the measure of effort assignment in each shot.

First, we consider a notion of effort assignment based on the nature of the shot. Precisely, we test whether the distance to the target is affected by the fact that relative performance in this shot determines whether the player or his opponent wins either a round, a set or the match, compared to a regular shot (omitted category). The first three columns of Table 4 report these regressions for the two treatments pooled together (model (1)), the Human treatment (model (2)) and the Robot treatment (model (3)). In model (1), we include a dummy variable indicating whether the player is interacting with a human opponent or with a robot.

In Table 4, model (2) indicates that, in most cases, round, set and match shots have no specific impact on performance compared to regular shots. Exceptions in the Human treatment are that performance is significantly better when it determines whether the player will win the round or whether the opponent will win the match. In the Robot treatment, it is marginally significantly better when it decides whether the opponent will win the round.

\footnotetext{
${ }^{9}$ Every $50 \mathrm{~ms}$, we draw two integer numbers, $\mathrm{lx}$ and ly in the interval [-5;5] with uniform probability. The player's pointer is modified by $\mathrm{lx}$ pixels on the $\mathrm{x}$-axis and ly pixels on the $\mathrm{y}$-axis. Let $L x=\left(l x_{i}\right)_{i \in[1 ; 5]}$ be the sequence of the five values of lx drawn before the player shot and $L y=\left(l y_{i}\right)_{i \in[1 ; 5]}$ be the sequence of the five values of ly drawn before the player shot. The value we report is $\left.S=\sqrt{(}\left(\sum_{i=1}^{5} l x_{i}\right)^{2}+\left(\sum_{i=1}^{5} l y_{i}\right)^{2}\right)$. Then, $\mathrm{S}$ is the distance between the positions of the pointer 0.25 seconds before the player's shot and at the time of the shot that is generated by the noise alone.

${ }^{10}$ We also tested the potential influence on the current distance of the emotional arousal experienced during the previous shot at the time of the feedback on one's score and on the trial's outcome. This requires dropping the observations relative to the first shot in the game. Since these two SCR measures were never significant, we do not include these variables in the regressions reported here and keep the data of all periods.
} 


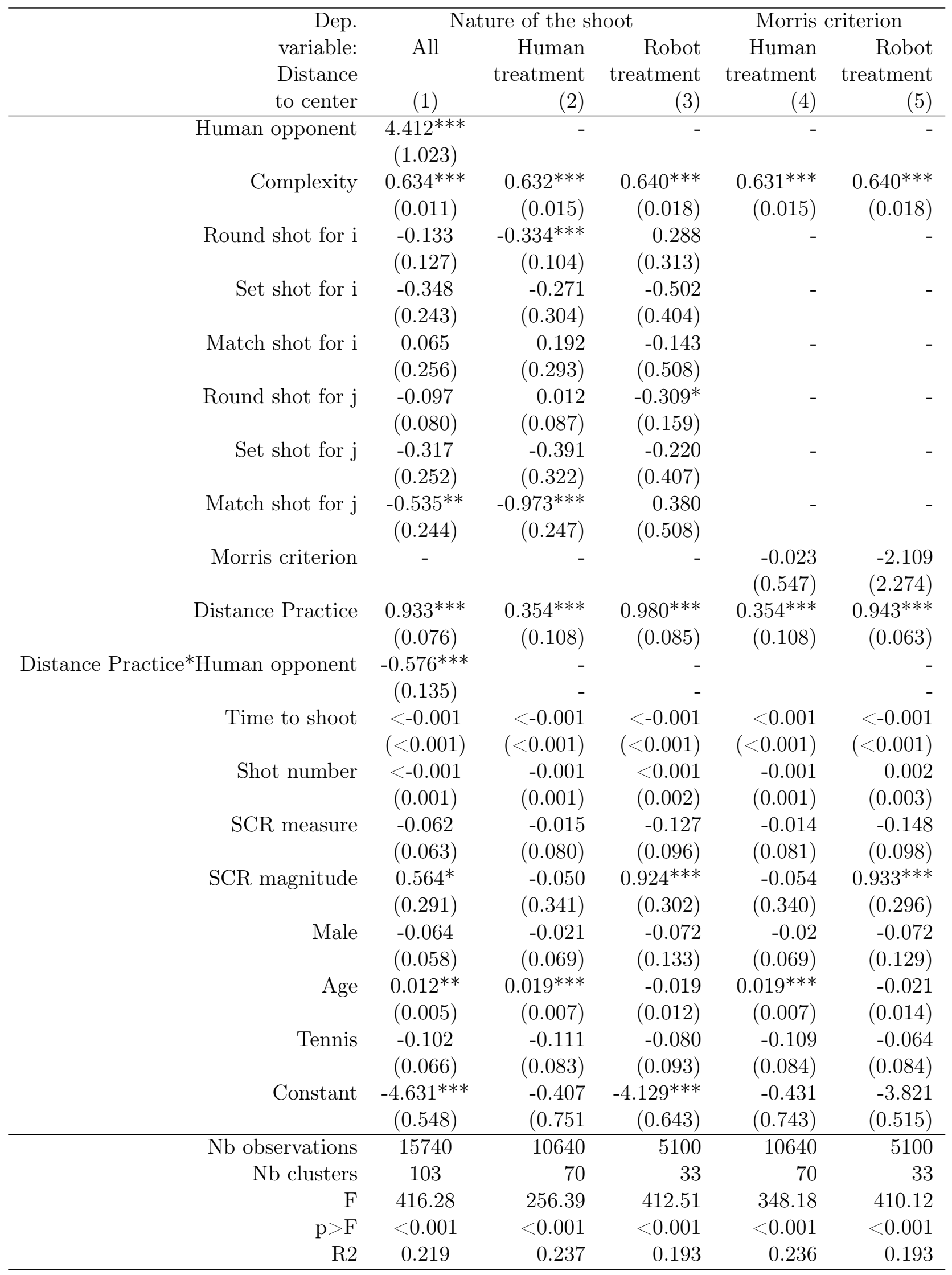

Table 4: Determinants of performance, including the nature of the shot or Morris-importance. 
Overall, however, considering only the local stake of a shot has very limited predictive value.

Our second measure of optimal effort assignment is based on the Morris criterion. It is calculated for each shot based on the percentage of ex ante chances each competitor has to win the game considering his relative performance in the ten practice shots. The last two columns of Table 4 report the estimates of the model in which we consider the value of the Morris-importance for each shot instead of the stake of the shot. Model (4) is for the Human treatment and model (5) for the Robot treatment. These two models show that the Morrisimportance attracts the predicted negative sign but it is far from reaching standard significance levels in any treatment. We then consider HNV-importance and present our second result.

Result 2: The HNV-importance for the optimal assignment of efforts predicts players' performance. This finding holds in the Human treatment when assuming that all players are endowed with the same stock of effort and in both treatments when allowing each player to differ in his stock of efforts.

Support for Result 2. In a dynamic setting, we consider that all players start the game with a stock of either $10,20,30,40$ or 50 efforts to assign during the match. We compute dynamically along the match on which points a subject should optimally use these 10, 20, 30, 40 or 50 efforts, based on his relative ability in the ten practice shots and knowing the actual duration of the game against his actual opponent. Indeed, we assume that players are able to form an expectation about the overall duration of the match, knowing their relative ability. We consider for each trial the incentive players have to use one effort, considering the stock of efforts left. For each initial stock of efforts among 10, 20, 30, 40, 50 we build the HNV-importance variable that takes value 1 or 0 , depending on whether the effort for the given stock should or not be invested in the current shot, as determined by our model.

In Table 5, we estimate five models explaining the distance to the target of the current shot in the Human treatment, one for each initial stock of optimal effort assignment between 10 and 50. We add the HNV criterion to the previous independent variables (Distance practice, complexity, time to shoot, shot number, recording of SCR, magnitude of SCR, gender, age, and practice of tennis). We construct the HNV allocation variable as follows: we consider 
that the match starts with players having an initial stock of efforts, $k$. Then, at the starting point, we compute whether a player has a positive incentive to use an effort using Definition 4. If it is not the case, the HNV allocation variable is 0 for this point and we proceed to the next point considering that this player keeps the same stock of efforts. If it is the case, then, the HNV allocation variable is 1 and we proceed to the next points of the actual game, only considering that, now, the player has only $k-1$ efforts left. Table A1 in Appendix displays the same models for the Robot treatment.

In all models but one (when we consider 40 optimal efforts to assign) in the Human treatment, the HNV criterion predicts the player's performance at the $5 \%$ or at the $1 \%$ significance level. In contrast, Table A1 in Appendix shows that in the Robot treatment the HNV allocation variable does not impact performance. This surprising finding indicates that when the player should rationally use one effort from his stock according to HNV theory, this indeed improves his performance by reducing the distance to the target, but exclusively when the player interacts with a human opponent. ${ }^{11}$ It suggests that when interacting with a robot, the impossibility to predict one's opponent effort in a specific moment of the match affects the ability of a player to assign his efforts according to the HNV-importance.

In each regression reported in Table 5, we forced each player to use the same initial stock of efforts. We now relax this constraint by allowing for individual heterogeneity in optimal effort assignment. In other words, we now consider the heterogeneity in individuals' critical ability, as shown by González-Díaz et al. (2012) about tennismen. To do so, we estimate for each individual which initial stock of efforts, between 10 and 50, fits the best his distance to the target throughout the game, with a linear model and robust standard errors. We consider five estimations for each individual, one for each possible initial stock of efforts, and include as independent variables the HNV allocation variable for this stock, the complexity of the current shot, the time to shoot, and the shot number. We compare the five regressions for each individual and retain the model -therefore the initial stock of optimal efforts for this player- that gives the highest t-value to the HNV allocation variable. ${ }^{12}$ Next, in Table 6 we

\footnotetext{
${ }^{11}$ Note that we also tested the same model considering the assignment of more than 50 units of effort. The HNV allocation variable remains significant at the $1 \%$ level. To save space, we omit these regressions here.

${ }^{12}$ For some individuals we have to reject the five regressions and assign to the player a missing HNV allo-
} 


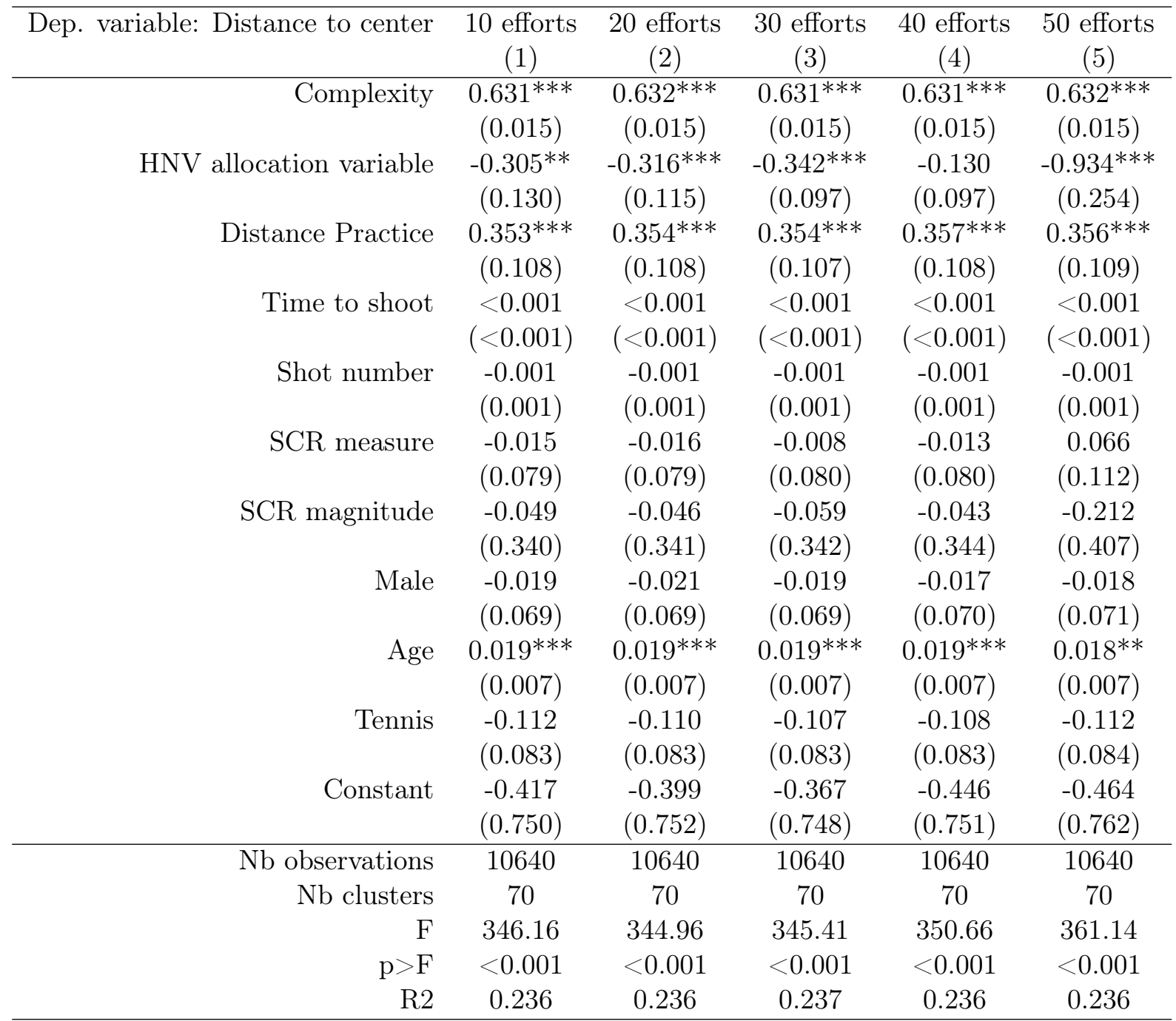

Note: All models are OLS regressions with robust standard errors (in parentheses) clustered at the individual level. ${ }^{* * *},{ }^{* *}$ and ${ }^{*}$ indicate significance at the $1 \%$ level, $5 \%$ level and $10 \%$ level, respectively.

Table 5: Determinants of performance in the Human treatment, based on the homogenous HNV-importance. 
report three regressions of the distance to the target, one for the treatments pooled together (1), one for the Human treatment (2) and one for the Robot treatment (3). The independent variables are the same as in Table 5, except that the HNV criterion now corresponds to different stocks of optimal effort assignment across players, as determined by the individual regressions.

Table 6 shows that if we allow for individual heterogeneity in the endowment in terms of effort stock, a shot with a higher importance according to the HNV allocation variable increases significantly the player's performance. This is observed regardless of whether the opponent is a human (model (2)) or a robot (model (3)). While the findings of Tables 5 and 6 are very consistent, Table 6 contradicts those of Table A1. This suggests that players behave more heterogeneously when they are facing a robot, as a general approach of effort assignment fails at predicting performance in this case. We finally introduce our last result.

Result 3: Emotional arousal hinders performance only when players are facing a robot, possibly because they cannot predict the strategy of their opponent.

Support for Result 3. Tables 4 to 6 show that having one's emotions recorded does not impact performance. For the average player, all else held constant, having a robot opponent has a positive impact on performance, except for those subjects who experience a greater SCR magnitude. In contrast, SCR never affects performance in the Human treatment. A possible explanation is that on average individuals feel less discouraged when losing points when they know they can ignore the strategy of the opponent since the robot is not reacting to their play. But the sub-sample of players who are more emotionally aroused when playing against a robot may see the competitive situation as more threatening than when opposed to a human, which affects their performance negatively. Blascovich et al. (2004) and Moore et al. (2012) for example have found a correlation between perception of threat, physiological reaction and performance in sport competitions; Buckert et al. (2015) have shown that perceiving competition as a threat tends to decrease a player's performance in the lab. A possible interpretation

cation variable. This occurs when the HNV allocation variable receives a positive coefficient (indicating that performance decreases when the point is more important in the sense of the HNV model). This corresponds to $7.14 \%$ of the players in the Human treatment and to $9.09 \%$ of the players in the Robot treatment (the difference is not statistically significant according to a proportion test). These observations are kept in the regressions and we include a dummy variable ("Missing HNV allocation") to the other independent variables. 


\begin{tabular}{|c|c|c|c|}
\hline $\begin{array}{l}\text { Dep. variable: } \\
\text { Distance to center }\end{array}$ & $\begin{array}{l}\text { All treatments } \\
\text { (1) }\end{array}$ & $\begin{array}{c}\text { Human treatment } \\
\text { (2) }\end{array}$ & $\begin{array}{c}\text { Robot treatment } \\
\text { (3) }\end{array}$ \\
\hline Human opponent & $3.896^{* * *}(0.958)$ & - & - \\
\hline Complexity & $0.640 * * *(0.017)$ & $0.631^{* * *}(0.015)$ & $0.640 * * *(0.018)$ \\
\hline Complexity*human & $-0.010(0.023)$ & - & - \\
\hline HNV allocation variable & $-0.898 * * *(0.170)$ & $-0.897 * * *(0.080)$ & $-0.898^{* * *}(0.171)$ \\
\hline HNV allocation variable*human & $0.001(0.187)$ & - & - \\
\hline Missing HNV allocation variable & $-0.145(0.090)$ & $-0.171^{* * *}(0.054)$ & $-0.145(0.091)$ \\
\hline Missing*human & $-0.026(0.105)$ & - & - \\
\hline Distance Practice & $0.978 * * *(0.068)$ & $0.339 * * *(0.114)$ & $0.978^{* * *}(0.068)$ \\
\hline Distance Practice*human & $-0.639 * * *(0.133)$ & - & - \\
\hline Time to shoot & $<-0.001(<0.001)$ & $<0.001(<0.001)$ & $<-0.001(<0.001)$ \\
\hline Time to shoot*human & $<0.001(<0.001)$ & - & - \\
\hline Shot number & $<0.001(0.002)$ & $-0.001(0.001)$ & $<0.001(0.002)$ \\
\hline Shot number*human & $-0.002(0.002)$ & - & - \\
\hline SCR measure & $-0.093(0.098)$ & $-0.031(0.083)$ & $-0.093(0.099)$ \\
\hline SCR measure *human & $0.062(0.129)$ & - & - \\
\hline SCR magnitude & $0.880 * * *(0.280)$ & $-0.058(0.342)$ & $0.880^{* * *}(0.283)$ \\
\hline SCR magnitude *human & $-0.938^{* *}(0.441)$ & - & - \\
\hline Male & $-0.047(0.124)$ & $-0.002(0.072)$ & $-0.047(0.125)$ \\
\hline Male*human & $0.049(0.143)$ & - & - \\
\hline Age & $-0.016(0.012)$ & $0.018^{* * *}(0.006)$ & $-0.016(0.012)$ \\
\hline Age*human & $0.034^{* *}(0.013)$ & - & - \\
\hline Tennis & $-0.068(0.095)$ & $-0.103(0.084)$ & $-0.068(0.096)$ \\
\hline Tennis*human & $-0.035(0.126)$ & - & - \\
\hline Constant & $-4.122^{* * *}(0.542)$ & $-0.226(0.791)$ & $-4.122^{* * *}(0.548)$ \\
\hline $\mathrm{Nb}$ observations & 15740 & 10640 & 5100 \\
\hline Nb clusters & 103 & 70 & 33 \\
\hline $\mathrm{F}$ & 441.56 & 319.72 & 492.06 \\
\hline $\mathrm{p}>\mathrm{F}$ & $<0.001$ & $<0.001$ & $<0.001$ \\
\hline $\mathrm{R} 2$ & 0.221 & 0.239 & 0.194 \\
\hline
\end{tabular}

Note: All models are OLS regressions with robust standard errors (in parentheses) clustered at the individual level. ${ }^{* * *},{ }^{* *}$ and $*$ indicate significance at the $1 \%$ level, $5 \%$ level and $10 \%$ level, respectively.

Table 6: Determinants of performance in the Human treatment, based on the heterogeneous HNV-importance. 
is that in our game, emotionally aroused players may be those who see a competition against a robot as more threatening than a competition against a human because they cannot predict the importance of the shot for the robot opponent.

Finally, it should be noted that almost all models show that performance decreases with the level of complexity of the shot and the player's age, and improves with his permanent ability. Other controls are never significant.

\section{Conclusion}

Successive tasks often do not have the same importance when it comes to achieve a final goal. A clear illustration is given by a tennis match but other examples can be found in the occupational domain (for example not all papers have the same importance when an academics apply for tenure or for full professorship). The present paper assesses whether performance increases according to the importance of the task to undertake and compares various theories related to this issue: choking under pressure and critical ability in relationship with the Morris-importance criterion. Each theory implies a specific relationship between performance and importance. In the first theory, performance is negatively correlated with the Morrisimportance, while in the second theory performance is positively correlated with importance. In this paper we measure the importance of a task not by the Morris-importance criterion but by the HNV-importance criterion. The latter assumes that the agent has a stock of exhaustible efforts and chooses the ideal moment to make an effort. An effort is used when the HNVimportance is higher. This paper tests experimentally these two approaches of importance, as well as a simple measure of importance based on critical shots (round/set/match shots). The experiment shows that the Morris-importance fails at predicting players' performance while the HNV allocation variable has a much better predictive value. Moreover, we do not clear evidence of the existence of choking under pressure: stress, as measured by the Skin Conductance Responses, does not affect performance. This contrasts notably with Apesteguia and Palacios-Huerta (2010).

Our criterion of HNV-importance takes into account the trade-off between the stakes and 
the option value for determining whether it is worthy to use or not an effort on a given task. However, the player does not take into account the other player's response to his own play. Our experiment consists of two treatments, the Human treatment and the Robot treatment. In most of our regressions, the HNV allocation variable predicts performance. Introducing strategic concerns in our theoretical framework seems to be an interesting extension that would move our theory from a decision theory setting to a game theory setting.

This study could of course be extended in several other ways. For instance, it could be promising to consider the case under which, after a certain delay, the agent can regain efforts. For example, studies have shown the existence of a momentum effect for the winner of a point in dynamic contests (Gauriot et al. (2014)). The idea that success breeds success could be captured in our model by an increase of the stock of efforts left during the match depending on success at previous important points. A preliminary stage where the agent could choose between two different assets- many lower-efficiency efforts or little high-efficiency efforts could also be considered. Indeed, a player while practicing may improve some characteristics: endurance or explosivity. This may apply to a sportsman, but also to a worker who may try to improve either his ability to work long hours on a project (the extensive margin), or his ability to react very quickly and intensively (the intensive margin). It might be also interesting to investigate the relation between efforts and tiredness. Indeed, an effort increases performance in the current task but it may also decrease performance in the following tasks, decreasing the mean performance of the agent in the rest of the competition. The agent faces then a trade-off: indeed, making an effort may shorten the competition but it may also affect negatively the future performance if the competition lasts. 


\section{References}

Apesteguia, J. and Palacios-Huerta, I. (2010). Psychological pressure in competitive environments: Evidence from a randomized natural experiment. The American Economic Review, 100(5):2548-2564.

Ariely, D., Gneezy, U., Loewenstein, G., and Mazar, N. (2009). Large stakes and big mistakes. The Review of Economic Studies, 76(2):451-469.

Baumeister, R. F. (1984). Choking under pressure: self-consciousness and paradoxical effects of incentives on skillful performance. Journal of personality and social psychology, 46(3):610.

Blascovich, J., Seery, M. D., Mugridge, C. A., Norris, R. K., and Weisbuch, M. (2004). Predicting athletic performance from cardiovascular indexes of challenge and threat. Journal of Experimental Social Psychology, 40(5):683-688.

Buckert, M., Schwieren, C., Kudielka, B. M., and Fiebach, C. J. (2015). How stressful are economic competitions in the lab? an investigation with physiological measures. Technical report, Discussion Paper Series, University of Heidelberg, Department of Economics.

Dawson, M. E., Schell, A. M., and Filion, D. L. (2007). The electrodermal system. Handbook of psychophysiology, 159.

Dohmen, T. J. (2008). Do professionals choke under pressure? Journal of Economic Behavior \& Organization, 65(3):636-653.

Gauriot, R., Page, L., et al. (2014). Does success breed success? a quasi-experiment on strategic momentum in dynamic contests. Technical report, QUT Business School.

González-Díaz, J., Gossner, O., and Rogers, B. W. (2012). Performing best when it matters most: Evidence from professional tennis. Journal of Economic Behavior \& Organization, $84(3): 767-781$.

Greiner, B. et al. (2004). The online recruitment system orsee 2.0-a guide for the organization 
of experiments in economics. University of Cologne, Working paper series in economics, 10(23):63-104.

Kocher, M. G., Lenz, M. V., and Sutter, M. (2012). Psychological pressure in competitive environments: New evidence from randomized natural experiments. Management Science, 58(8):1585-1591.

Magnus, J. and Klaassen, F. (1998). On the existence of âĂIJbig pointsâĂİ in tennis: four years at wimbledon. CentER for Economic Research, Tilburg University.

Moore, L. J., Vine, S. J., Wilson, M. R., and Freeman, P. (2012). The effect of challenge and threat states on performance: An examination of potential mechanisms. Psychophysiology, 49(10):1417-1425.

Morris, C. (1977). The most important points in tennis. Optimal strategies in sports, 5:131140.

Norris, J. (1998). Markov Chains, volume 2. Cambridge University Press.

Paserman, M. D. (2007). Gender differences in performance in competitive environments: Evidence from professional tennis players. CEPR Discussion Papers 6335, C.E.P.R. Discussion Papers. 


\section{A Appendices}

\section{A.1 Illustration of Morris-importance and $\mathrm{HNV}(k)$-importance for tennis scores}

Consider a tennis match between player 1 and player 2. Obviously, they both have the objective to win the match. We do not consider service and receive.

\section{A.1.1 Illustration of Morris-importance and $\mathrm{HNV}(k)$-importance for a single game}

We first focus on a single game and we assume that the player who wins the game is declared victorious. Note that a margin of two points is required. We assume that the probability to win one point is the same for both players $(p=0.5)$.

Illustration of a single game. The X-axis (the Y-axis, respectively) counts the gains of player 1 (player 2, respectively). Each square in Figure A1 represents a potential point. The first square in the lower part of the figure on the left illustrates the starting point in the game $(0,0)$. The square on the right (above) depicts the score if player 1 (player 2) has won the point.

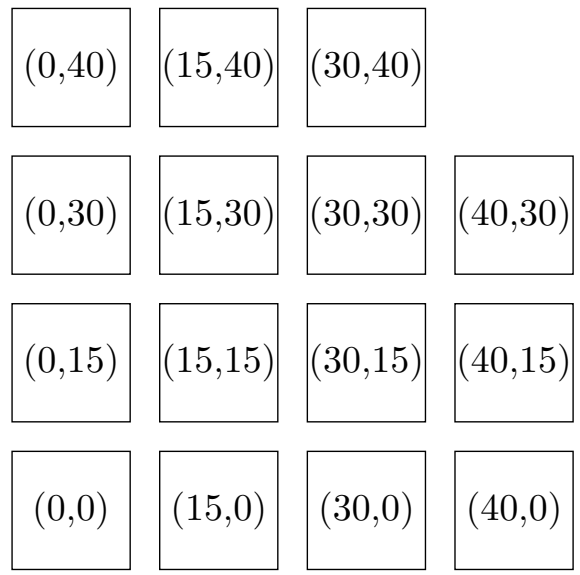

Figure A1: Illustration of a single game. 

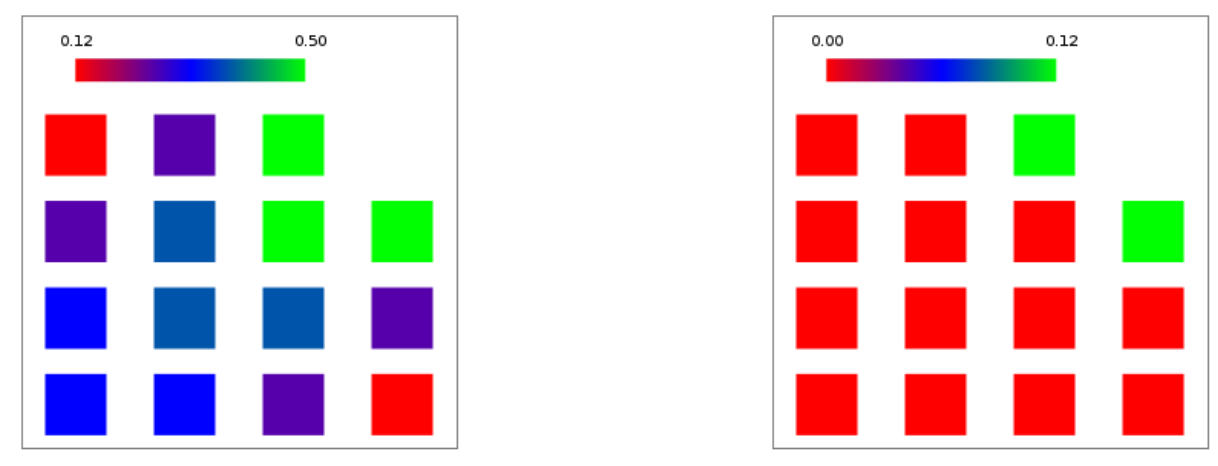

Figure A2: Morris-importance (left) and HNV(1)-importance (right) for all the scores of a single game for $p=0.5$.

Morris-importance and HNV(1)-importance. We calculate, for each point, focusing on player 1's point-of-view, both Morris-importance and HNV(1)-importance. We illustrate these results in Figure A2. The following colour codes are used: green means high importance, light blue means somewhat high, dark blue means medium importance, purple means somewhat low importance and red means low importance.

Note that the two panels in Figure A2 are symmetric. Indeed, the probability to win one point is the same for both players. First of all, Morris-importance is the highest for the scores $(30,30),(30,40)$ and $(40,30)$. Morris-importance is the lowest when the score difference is equal to three points, i.e. for the scores $(0,40)$ and $(40,0)$. The closer to the end of the game players are, the less likely the one who loses this point may win the game. In the case of a single effort left there are only two possibilities: the player has incentives to make an effort or not. Player 1 has positive incentives to exert effort only for $(30,40)$ and $(40,30)$. If player 1 wins at $(30,40)$, the score will be draw $(30,30)$, otherwise he will lose the match. In the case of $(40,30)$, either he wins the match or there is draw.

We consider five different cases:

- For $(30,40)$ and $(40,30)$, the two measures are similar and high. 
- For $(30,30)$ the Morris-importance is high although while player 1 has no incentives to make an effort. The intuition is the following. This point is not irreversible. If player 1 looses this point, he can always make an effort after and comes back to draw.

- For $(15,15),(30,15)$ and $(15,30)$, player 1 has no incentives to make an effort. Winning these points modifies the probability to win the game but these points are not irreversible: it is better to keep the effort and use it latter.

- For the scores $(0,0),(0,15)$ and $(15,0)$, the Morris-importance is medium while HNV(1)importance is low.

- For the other scores, the two measures are similar and insignificant.

To conclude, there are only two possibilities: the player has incentives to make an effort or not. The closer to the end of the match players are, the less likely the player who loses this point may win the game. In other words, the closer to the end of the game the score is, the higher the HNV(1)-importance will be. We also show that the two measures are similar only at the end of a tight game or when the game is fairly one-sided and far from the end.

Two exhaustible efforts and HNV(2)-Importance. We also analyze the situation in which the player has two efforts left. Figure A3 depicts HNV(2)-importance for a single game. Note that when player 1 has two efforts left, the points for which he has incentives to use the first effort are clearly different from those for which he has incentives to use the second. The intuition is the following: with two remaining efforts, the goal is using the first effort to avoid losing the game with a close score and use the last effort to win the game. 


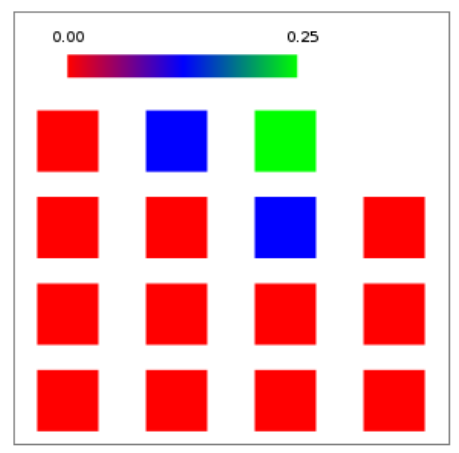

Figure A3: $\mathrm{HNV}(2)$-importance for $p=0.5$.

\section{A.1.2 Morris-importance and HNV(1)-importance for all the scores of a whole match.}

We consider now a whole match and we calculate the Morris-importance and the HNV(1)importance for all the potential points, for the probability $\mathrm{p}=0.5$. The results for a whole match extend the observations for a single game. Figures A4 and A5 illustrate Morris-importance and $\operatorname{HNV}(1)$-importance for all the scores of a whole match with $\mathrm{p}=0.5$ and where the first player to win two sets is victorious.

- The X-axis (the Y-axis, respectively) displays the gains of player 1 (player 2, respectively).

- Each small square depicts a point. A game is modeled as previously.

- The same rules as in the experiment are used. The first of the two competitors who wins at least 4 points with at least 2 points ahead of the opponent wins the round. The first of the two competitors who wins 6 rounds wins the set. The first of the two competitors who wins 2 sets wins the match.

- We use the same colour codes as previously: high importance (green), somewhat high 
importance (light blue), middle importance (dark blue), somewhat low importance (purple), low importance (red).

The figures show that the two measures are similar only at the end of a tight match and when the match is fairly one-sided and far from the end. The notion of irreversibility is crucial. When the match is tight, the individual should make an effort on the tasks which lead to an irreversibility: if this point is lost, the victory is almost impossible. 


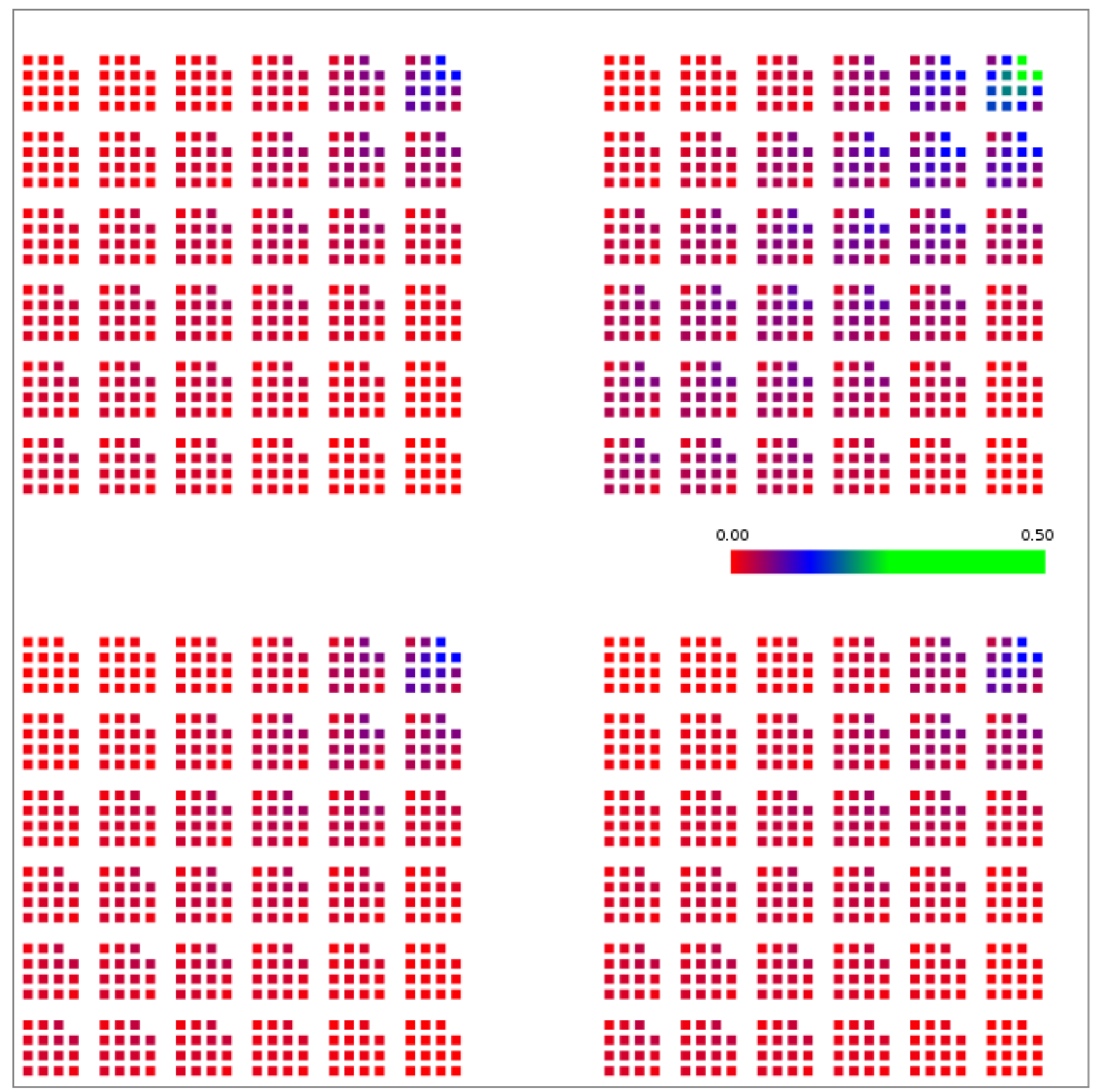

Figure A4: Morris-importance for all the scores of a whole game for $p=0.5$. 


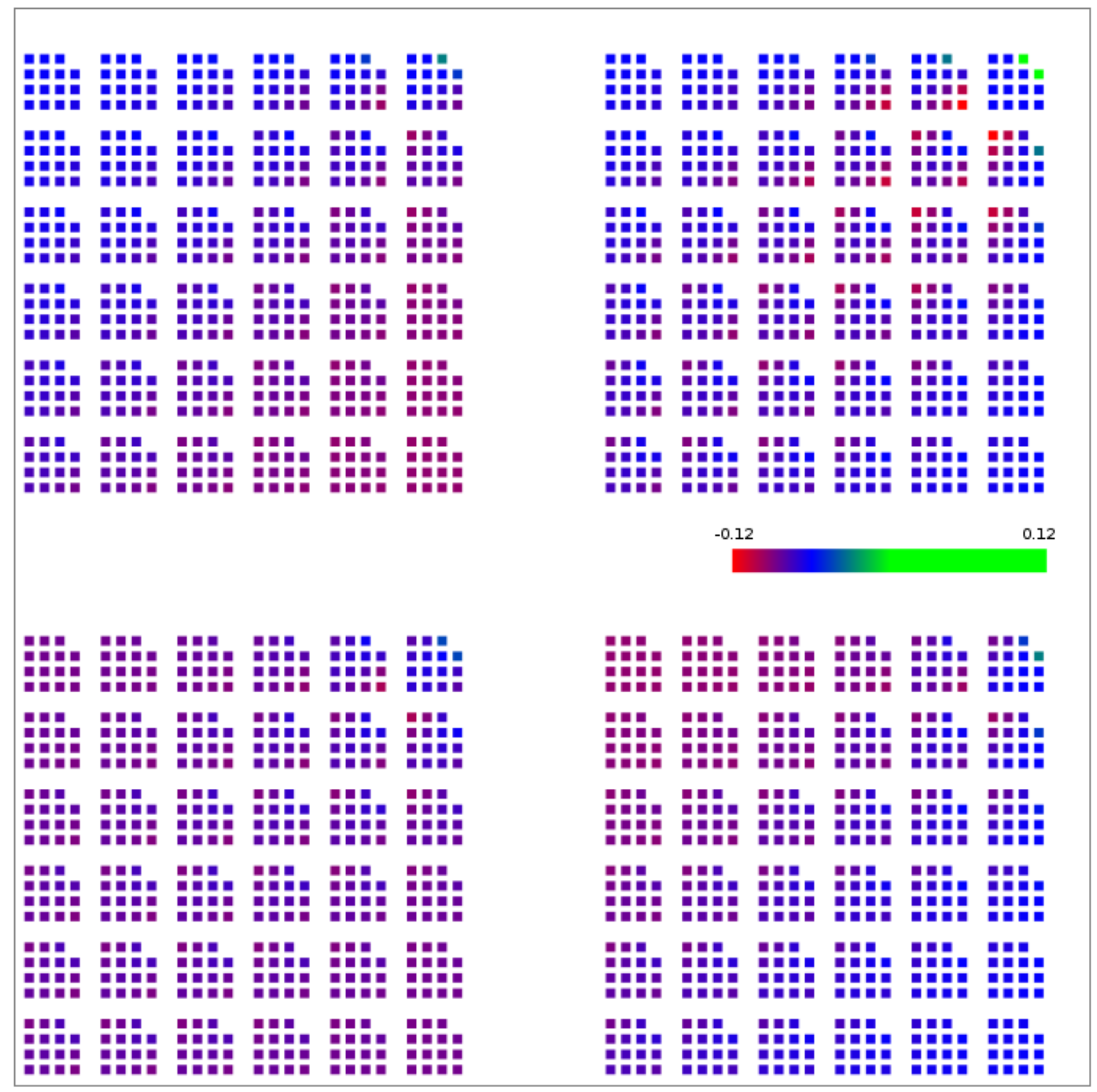

Figure A5: HNV(1)-importance for all the scores of a whole game for $p=0.5$. 


\section{A.2 Instructions for the experiment}

These instructions, translated from French, are both for the Human treatment and the Robot treatment. When the instructions differ between the two treatments, those specific to the Robot treatment are put in italics and into brackets.

We thank you for participating in this experiment in economics in which you can earn a certain amount of money. You will also receive a 5 euros participation fee for showing up on time. You will be paid in cash and in private at the end of the session.

Throughout the session, we ask you not to communicate with other participants. All information entered into the computer will remain anonymous.

\section{Description}

This experience consists of one part in which you will be paired with one other person in the room. The identity of this person will remain unknown. Similarly, the other person with whom you will be paired will never be informed of your identity. This person will be called your "opponent" in the remainder of these instructions.

[Previous paragraph replaced by the following in the Robot treatment: This experience consists of one part in which you will be paired with one other player. This player is not a person, it is a computer. This player will be called your "opponent" in the remainder of these instructions.]

Your earnings in this part depend on your performance and of that of your opponent during the game. In addition to the participation fee, one of the two co-participants will earn 20 Euros and the other will earn 0 Euro, according to the rules detailed below.

/Previous sentence replaced by the following in the Robot treatment: In addition to the participation fee, you will earn either 20 Euros or 0 Euro, according to the rules detailed below.] 
This part consists of several stages; each stage is divided into several rounds. During each round, we ask you to perform the task described below.

The task The task consists of using your mouse pointer to reach the center of a target that appears on your computer screen. You have to shoot as accurately as possible in the center of the target. The difficulty differs according to a perturbation of the position of the pointer which is random in each shot. The difficulty is the same for each participant.

Each participant has 8 seconds maximum to shoot. If the shot was not performed before the 8 seconds have elapsed, the distance to the target center is arbitrarily set to 1000 .

During each round, you will have to shoot several times.

JOnly in the Robot treatment:

How does your computer-opponent play?

For each shot of your robot, the program randomly selects a shot among the shots of the human participants in a previous session. During this previous session, only human participants were involved and they were paired together randomly. The "robot shot" is therefore not random: it is the shot of a human participant in a previous session aimed at the center of the target.]

Performance and the number of points Your performance in this task is indicated by the distance between the impact of your shot and the center of the target. The smaller is this distance, the better is your performance.

Once the two co-participants have shot, the performances of the two co-participants are compared. The co-participant with the best performance (that is to say, the lowest distance to the center of the target) scores one point.

In case of a tie between the two co-participants, a random draw determines which of the two participants is awarded the point.

The first of the two co-participants who wins at least 4 points with at least 2 points ahead of the opponent wins the round.

The first of the two co-participants who wins 6 rounds wins the set.

The first of the two co-participants who wins 2 sets wins the game. 
Determination of payoffs Within the pair, if you win the game you earn 20 Euros in addition to your participation fee. If you do not win the game, you earn nothing; you only receive your participation fee.

Information As shown in the screenshot below, the screen displays a target. Below the target you can see a time counter that indicates the remaining time to shoot. After each shot, you are informed on your screen of your performance and that of your opponent. Finally, you are informed on whether you or your opponent scores the current point. The bottom of the screen permanently shows:

- the number of sets won so far,

- the number of rounds won in the current set,

- the number of points earned in the current round, both for yourself and for your opponent.

Your screen also informs you whether the next shot is a shot that decides the winner of the round, the set or game.

Beginning of the session Before the game starts, you have to make 5 test shots and 10 practice shots. The five test shots are intended to familiarize you with the task. After each shot, you are informed of your own performance (your distance to the center of the target).

The 10 practice shots are used to calculate your ability at this task compared to that of your opponent. After each of these shots, you are informed of your own performance.

After the 10 practice shots, the computer program compares your performance in each of the 10 practice shots to the performance of your opponent in each of those 10 shots, taking into account all the possible combinations of these shots. The shots that have not been done in the allotted time are not included in this calculation. This calculation will tell you what is the theoretical number of chances out of 100 that you should win the point on your opponent for a given shot.

Your performance during these test and practice shots will not be taken into account in the calculation of the points in the actual game. 


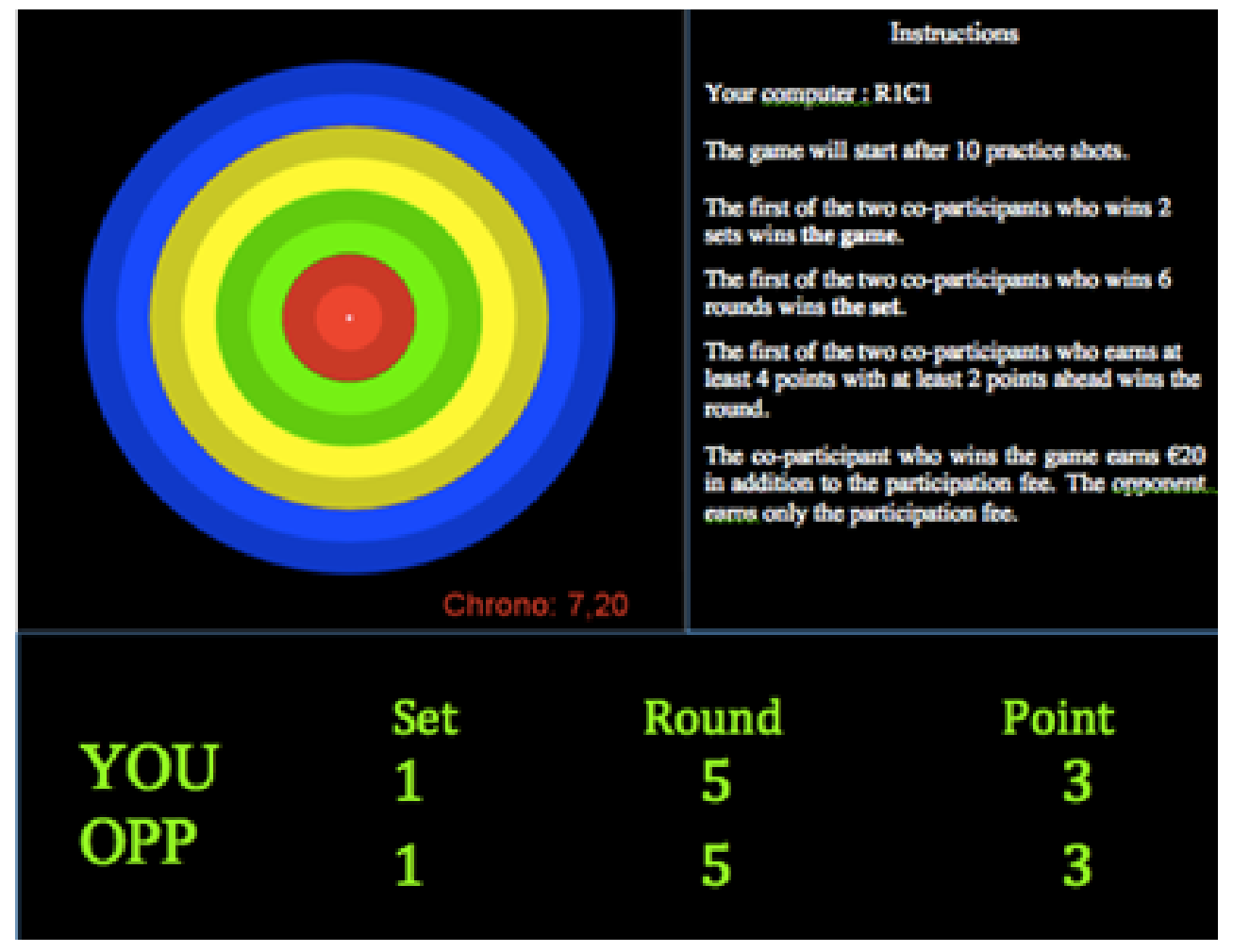

Figure A6: Screenshot of the task. 
End of the session At the end of the game, you will see on your screen a final questionnaire. Once you have completed this questionnaire, we ask you to wait quietly until the end of the session without communicating with other participants. The session will end once all session participants have finished their game. To wait, you can read the magazines that are available on your desk or any document that you brought with you. You can also enjoy all the activities that will be available on your computer screen.

To sum up:

- The task consists of shooting on a target.

- The winner of the game earns 20 Euros and the loser gets 0 .

- The winner of the game is the one of the two co-participants who won two sets.

- To win a set, one must be the first co-participant to win 6 rounds.*

- To win a round, one must be the first co-participant to win at least 4 points with at least 2 points ahead of his opponent.

Please read these instructions again and answer the questionnaire that was distributed. If you have any question, please raise your hand and we will answer your questions in private. Once you have completed the questionnaire, raise your hand so we can come and check your answers.

\section{Questionnaire}

Thank you for answering these questions to familiarize yourself with the rules of the experiment. 


\begin{tabular}{lrr}
\hline Propositions & Yes & No \\
\hline [Robot treatment: You play against another person present in the room.] & $\mathrm{O}$ & $\mathrm{O}$ \\
In a round, imagine the current score: & & \\
3 points for participant 1 and 2 points for participant 2. & $\mathrm{O}$ & $\mathrm{O}$ \\
- Does participant 1 win the round by winning the next point? & $\mathrm{O}$ & $\mathrm{O}$ \\
- Does participant 2 win the round by winning the next point? & & \\
Does a participant win the set as soon as the participant & $\mathrm{O}$ & $\mathrm{O}$ \\
has won one round more than the opponent? & $\mathrm{O}$ & $\mathrm{O}$ \\
The game ends as soon as a participant has won two sets. & $\mathrm{O}$ & $\mathrm{O}$ \\
The earnings of each set are 20 Euros. & $\mathrm{O}$ & $\mathrm{O}$ \\
There may be three sets in the game. & $\mathrm{O}$ & $\mathrm{O}$ \\
There may be four sets in the game. &
\end{tabular}

\section{A.3 Determinants of performance in the Robot treatment}




\begin{tabular}{|c|c|c|c|c|c|}
\hline $\begin{array}{l}\text { Dep. variable: } \\
\text { Distance to center }\end{array}$ & $\begin{array}{l}10 \text { efforts } \\
\text { (1) }\end{array}$ & $\begin{array}{l}20 \text { efforts } \\
\text { (2) }\end{array}$ & $\begin{array}{l}30 \text { efforts } \\
\text { (3) }\end{array}$ & $\begin{array}{l}40 \text { efforts } \\
\text { (4) }\end{array}$ & $\begin{array}{l}50 \text { efforts } \\
\text { (5) }\end{array}$ \\
\hline Complexity & $\begin{array}{c}0.640^{* * *} \\
(0.018)\end{array}$ & $\begin{array}{c}0.640^{* * *} \\
(0.018)\end{array}$ & $\begin{array}{c}0.640^{* * *} \\
(0.018)\end{array}$ & $\begin{array}{c}0.640^{* * *} \\
(0.018)\end{array}$ & $\begin{array}{c}0.640^{* * *} \\
(0.018)\end{array}$ \\
\hline HNV allocation variable & $\begin{array}{l}-0.216 \\
(0.247)\end{array}$ & $\begin{array}{l}-0.084 \\
(0.222)\end{array}$ & $\begin{array}{l}-0.181 \\
(0.177)\end{array}$ & $\begin{array}{l}-0.121 \\
(0.180)\end{array}$ & $\begin{array}{c}0.403 \\
(0.506)\end{array}$ \\
\hline Distance Practice & $\begin{array}{c}0.973^{* * *} \\
(0.084)\end{array}$ & $\begin{array}{c}0.972^{* * *} \\
(0.084)\end{array}$ & $\begin{array}{c}0.972^{* * *} \\
(0.083)\end{array}$ & $\begin{array}{c}0.975^{* * *} * \\
(0.081)\end{array}$ & $\begin{array}{c}0.968^{* * *} \\
(0.084)\end{array}$ \\
\hline Time to shoot & $\begin{array}{l}<-0.001 \\
(<0.001)\end{array}$ & $\begin{array}{l}<-0.001 \\
(<0.001)\end{array}$ & $\begin{array}{l}<-0.001 \\
(<0.001)\end{array}$ & $\begin{array}{l}<-0.001 \\
(<0.001)\end{array}$ & $\begin{array}{l}<-0.001 \\
(<0.001)\end{array}$ \\
\hline Shot number & $\begin{array}{c}0.001 \\
(0.002)\end{array}$ & $\begin{array}{c}0.001 \\
(0.002)\end{array}$ & $\begin{array}{l}<0.001 \\
(0.002)\end{array}$ & $\begin{array}{l}<0.001 \\
(0.002)\end{array}$ & $\begin{array}{l}<0.001 \\
(0.002)\end{array}$ \\
\hline SCR measure & $\begin{array}{l}-0.132 \\
(0.093)\end{array}$ & $\begin{array}{l}-0.133 \\
(0.093)\end{array}$ & $\begin{array}{l}-0.133 \\
(0.093)\end{array}$ & $\begin{array}{l}-0.128 \\
(0.092)\end{array}$ & $\begin{array}{l}-0.131 \\
(0.094)\end{array}$ \\
\hline SCR magnitude & $\begin{array}{c}0.908^{* * *} * \\
(0.296)\end{array}$ & $\begin{array}{c}0.913^{* * *} \\
(0.296)\end{array}$ & $\begin{array}{c}0.909 * * * \\
(0.295)\end{array}$ & $\begin{array}{c}0.913^{* * *} \\
(0.293)\end{array}$ & $\begin{array}{c}0.922^{* * *} \\
(0.297)\end{array}$ \\
\hline Male & $\begin{array}{l}-0.065 \\
(0.133)\end{array}$ & $\begin{array}{l}-0.065 \\
(0.134)\end{array}$ & $\begin{array}{l}-0.065 \\
(0.134)\end{array}$ & $\begin{array}{l}-0.068 \\
(0.131)\end{array}$ & $\begin{array}{l}-0.066 \\
(0.133)\end{array}$ \\
\hline Age & $\begin{array}{l}-0.018 \\
(0.012)\end{array}$ & $\begin{array}{l}-0.019 \\
(0.012)\end{array}$ & $\begin{array}{l}-0.019 \\
(0.012)\end{array}$ & $\begin{array}{l}-0.018 \\
(0.012)\end{array}$ & $\begin{array}{l}-0.019 \\
(0.012)\end{array}$ \\
\hline Tennis & $\begin{array}{l}-0.084 \\
(0.093)\end{array}$ & $\begin{array}{l}-0.082 \\
(0.092)\end{array}$ & $\begin{array}{l}-0.083 \\
(0.092)\end{array}$ & $\begin{array}{c}-0.073 \\
(0.0991)\end{array}$ & $\begin{array}{l}-0.077 \\
(0.092)\end{array}$ \\
\hline Constant & $\begin{array}{c}-4.111^{* * *} \\
(0.619)\end{array}$ & $\begin{array}{c}-4.089^{* * *} \\
(0.610)\end{array}$ & $\begin{array}{c}-4.060^{* * *} \\
(0.616)\end{array}$ & $\begin{array}{c}-4.103^{* * *} \\
(0.604)\end{array}$ & $\begin{array}{c}-4.059^{* * *} \\
(0.621)\end{array}$ \\
\hline Nb observations & 5100 & 5100 & 5100 & 5100 & 5100 \\
\hline Nb clusters & 33 & 33 & 33 & 33 & 33 \\
\hline $\mathrm{F}$ & 413.37 & 415.64 & 414.39 & 484.39 & 408.85 \\
\hline $\mathrm{p}>\mathrm{F}$ & $<0.001$ & $<0.001$ & $<0.001$ & $<0.001$ & $<0.001$ \\
\hline $\mathrm{R} 2$ & 0.192 & 0.192 & 0.192 & 0.192 & 0.192 \\
\hline
\end{tabular}

Note: All models are OLS regressions with robust standard errors (in parentheses) clustered at the individual level. ${ }^{* * *},{ }^{* *}$ and ${ }^{*}$ indicate significance at the $1 \%$ level, $5 \%$ level and $10 \%$ level, respectively.

Table A1: Determinants of performance in the Robot treatment, based on the homogenous HNV importance. 